\title{
Precipitation at Dumont d'Urville, Adélie Land, East Antarctica: the APRES3 field campaigns dataset
}

\author{
Christophe Genthon $^{1}$, Alexis Berne ${ }^{2}$, Jacopo Grazioli ${ }^{3}$, Claudio Durán Alarcón ${ }^{1}$, Christophe Praz ${ }^{2}$, and \\ Brice Boudevillain ${ }^{1}$ \\ ${ }^{1}$ Univ. Grenoble Alpes, CNRS, IRD, Grenoble INP, IGE, 38000 Grenoble, France \\ ${ }^{2}$ Environmental Remote Sensing Laboratory, Environmental Engineering Institute, School of Architecture, \\ Civil and Environmental Engineering, École Polytechnique Fédérale de Lausanne, 1015 Lausanne, Switzerland \\ ${ }^{3}$ Federal Office of Meteorology and Climatology, MeteoSwiss, Locarno-Monti, Switzerland \\ Correspondence: Christophe Genthon (christophe.genthon@cnrs.fr) \\ Received: 12 March 2018 - Discussion started: 26 April 2018 \\ Revised: 23 July 2018 - Accepted: 6 August 2018 - Published: 6 September 2018
}

\begin{abstract}
Compared to the other continents and lands, Antarctica suffers from a severe shortage of in situ observations of precipitation. APRES3 (Antarctic Precipitation, Remote Sensing from Surface and Space) is a program dedicated to improving the observation of Antarctic precipitation, both from the surface and from space, to assess climatologies and evaluate and ameliorate meteorological and climate models. A field measurement campaign was deployed at Dumont d'Urville station at the coast of Adélie Land in Antarctica, with an intensive observation period from November 2015 to February 2016 using X-band and K-band radars, a snow gauge, snowflake cameras and a disdrometer, followed by continuous radar monitoring through 2016 and beyond. Among other results, the observations show that a significant fraction of precipitation sublimates in a dry surface katabatic layer before it reaches and accumulates at the surface, a result derived from profiling radar measurements. While the bulk of the data analyses and scientific results are published in specialized journals, this paper provides a compact description of the dataset now archived in the PANGAEA data repository (https://www.pangaea.de, https://doi.org/10.1594/PANGAEA.883562) and made open to the scientific community to further its exploitation for Antarctic meteorology and climate research purposes.
\end{abstract}

\section{Introduction}

The Antarctic ice sheet is a huge continental storage of water which, if altered through climate change, has the potential to significantly affect global sea level. While climate models consistently predict an increase in precipitation in the future in Antarctica (e.g. Palerme et al., 2016), most of which falls in the form of snow that will not melt and thus will accumulate further ice, observational data to raise confidence in the current precipitation in the models are still in demand. Antarctica is the poor cousin of global continental precipitation observation and climatology building efforts: citing Schneider et al. (2014) of the Global Precipitation Climatology Center (GPCC), "The GPCC refrains from providing a (precipitation) analysis over Antarctica" because of poor data coverage. The GPCC's global maps of continental precipita- tion from in situ observations are left blank only over Antarctica. Satellites offer rising prospects to monitor remote, difficult and/or uninhabited regions, but even then Antarctica tends to be excluded from comprehensive and/or global studies (e.g. Funk et al., 2015). Only those studies that specifically focus on the polar regions and Antarctica have presented and discussed aspects of the Antarctic precipitation by satellite (Palerme et al., 2014, 2016, 2017; Behrangi et al., 2016). However, ground-based observations are still lacking to suitably calibrate and validate the satellite products.

The measurement of solid precipitation is notoriously difficult (Goodison et al., 1998; Nilu, 2013). Difficulties are exacerbated in Antarctica because access and operations are logistically difficult and environmental conditions are extreme. Antarctica is the driest continent on Earth in terms of pre- 
cipitation: satellite data estimate the mean precipitation at $171 \mathrm{~mm} \mathrm{yr}^{-1}$ of water equivalent north of $81^{\circ} \mathrm{S}$, the latitude reached by the polar orbiting satellites (Palerme et al., 2014). Low precipitation is supported by net accumulation measurements at the surface using glaciological methods (Eisen et al., 2007) which yield equally low numbers (Arthern et al., 2006). On the high Antarctic plateau, the accumulation is only a few $\mathrm{cm} \mathrm{yr}^{-1}$ annually (e.g. Genthon et al., 2015). Such a low precipitation rate would be very hard to monitor even in more hospitable environments. It is not possible with conventional instruments in Antarctica. Satellite data and glaciological reconstructions, as well as models and meteorological analyses, support a dry interior but indicate that precipitation is much larger at the peripheries of the Antarctic ice sheet, yearly reaching several tens of centimetres, or even metres, locally (Palerme et al. 2014). However, strong katabatic winds frequently blow at the peripheries, which adversely affect the conventional precipitation measurement methods. Collecting instruments (bucket-style instruments that capture and collect to measure snowfall, typically by weighing or tipping bucket counts) actually undercatch or overcatch because of air deflection and turbulence caused by the instruments themselves. In addition, they catch not only fresh falling snow, but also drifting/blowing snow which was previously deposited at the surface, and then eroded and remobilized by the strong winds. Non-catching instruments, including in situ (disdrometer) and remote (radar, lidar) sensing instruments, offer interesting prospects. Radars are particularly attractive because they can profile through the air layers. They can sense both horizontally to expand the spatial significance of the measurement and vertically to scan the origin and fate of precipitation since condensation in the atmospheric column, from the clouds (see Witze, 2016, for an application in Antarctica) and above to the surface, and separate blowing snow in the lower layers from precipitation higher up.

However, while radars are customarily used in other regions to monitor liquid precipitation (e.g. Krajewski and Smith, 2002; Fabry, 2015), and many campaigns have also been conducted in high-latitude and high-altitude regions to study snowfall (e.g. Schneebeli et al., 2013; Grazioli et al., 2015; Medina and Houze, 2015; Moisseev et al., 2015; Kneifel et al., 2015), experience is still limited in the Antarctic environment (Gorodetskaya et al., 2015). Because such instruments do not collect and directly measure the mass of falling precipitation, but rather measure the fraction of an emitted radiation which is reflected back by the hydrometeors, quantification in terms of precipitation involves both physically based (electromagnetic laws of diffusion, diffraction and propagation) and hypothesis-based (particle population size and shape, habits) post-processing. The hypothesisbased part requires calibration and validation using various sources of in situ measurements (e.g. Souverijns et al., 2017).

As part of the APRES3 project (Antarctic Precipitation, Remote Sensing from Surface and Space, http://apres3.osug. fr, last access: 1 August 2018), starting in November 2015 until February 2016 for the intense observing period but still ongoing for some observations, an unprecedentedly comprehensive field campaign was launched at the French Dumont d'Urville Antarctic scientific station at the coast of Adélie Land. The objective was to measure and monitor precipitation not only in terms of quantity, but also of falling snow particle characteristics and microphysics. The range of instruments included a profiling K-band and a polarimetric scanning X-band radar, a multi-angle snowflake camera (MASC), an OTT Pluvio2 weighing gauge, and a Biral VPF-730 disdrometer. A weather station reporting temperature, moisture and wind conditions near the instruments was also deployed. Finally, a depolarization lidar was tentatively operated but had problems and is not further mentioned here. All instruments were removed at the end of January 2016 except the K-band radar, which remained in operation throughout 2016 and beyond. Grazioli et al. (2017a) provide a comprehensive description of the data and analysis techniques and discuss scientific outcomes. Further work is ongoing to address the calibration and validation of meteorological and climate models and of satellite remote sensing techniques with the data (snowfall occurrences and rates, but also vertical profiles). Meanwhile, because this is a unique dataset, dissemination to the wider community for similar use with other models and remote sensing processing approaches or other research purposes is considered timely. This paper provides a compact description of the dataset and dissemination.

\section{Dataset description}

Grazioli et al. (2017a) provide ample information on the observation site, most instruments and methods. A summary and complementary information are provided below.

\subsection{Site description}

The main APRES3 (austral) summer field campaign took place at French Antarctic scientific station Dumont d'Urville (DDU) in Adélie Land $\left(66.6628^{\circ} \mathrm{S}, 140.0014^{\circ} \mathrm{E} ; 41 \mathrm{~m}\right.$ a.s.l. on average). The station is on Petrel Island located only $\sim 5 \mathrm{~km}$ off the continent and the ice sheet proper: the observations are thus representative of the very coast of the Antarctic ice sheet. Because the station was operated for more than 60 years uninterruptedly, the means and statistics of meteorology and climate are documented (König-Langlo et al., 1998; Grazioli et al., 2017a). A main meteorological feature is the strong katabatic winds that frequently blow in the area. Adélie Land was coined "the home of the blizzard" by Mawson (1915) after the first Australian Antarctic winter over in this region. However, much of the coasts of Antarctica are affected by the katabatic winds (Parish and Bromwich, 1987). DDU is a perfect place to sample their consequences, including in relation to precipitation. 


\subsection{Observations and instruments}

Standard measurements of atmospheric variables (temperature, wind speed, wind direction, relative and specific humidity, atmospheric pressure) are collected regularly all year long by the French meteorological service (Météo France), and a radiosounding is made daily at 00:00 UTC. The routine program does not involve any instrumental measurement of precipitation. There are reports of visual estimation of the occurrence and type in the METAR (METeorological Airport Report) convention, but no quantification. For the APRES3 campaign, several instruments were deployed from the beginning of November 2015 to the end of January 2016 to objectively characterize and quantify the occurrences and amounts of precipitation, as described below.

\subsubsection{Surface-based remote sensing instruments}

As reported in the introduction, traditional collecting precipitation gauges are unreliable in Antarctica in general, and in particular in the coastal regions strongly affected by katabatic winds. Radars are the core instruments of the APRES3 campaign. Radars remotely sense the hydrometeors, estimate quantities and speed, and from this derive precipitation rates. Radars can scan and profile through atmospheric and hydrometeor layers and look beyond blowing snow near the surface. Two radars were deployed: a K-band frequencymodulated continuous-wave vertically staring profiler and an X-band pulsed dual-polarization scanning Doppler radar. The first instrument, a Metek micro-rain radar (MRR), is designed to measure rainfall rather than snowfall using the backscattering and vertical velocity information. However, the raw Doppler spectra can be reprocessed using Maahn and Kollias (2012)'s improved and innovative processing chain for data collected in snow to retrieve Doppler radar moments such as reflectivity Z and Doppler velocity. Most Z-S relations for radars have been derived for 10,35 or $94 \mathrm{GHz}$ and therefore the measured equivalent radar reflectivity at $24 \mathrm{GHz}$ is first converted to X-band. Once mapped to Xband reflectivity this can be converted to snowfall rate $\mathrm{S}$ by means of a Z-S power law fitted to the local conditions using the weighing gauge information or parameterizations from the existing literature (for more details, see Grazioli et al., 2017a). The MRR was used with a $100 \mathrm{~m}$ vertical resolution. The second instrument, a mobile X-band polarimetric radar (MXPol), for which extensive experience with the measurement of snow is available (Schneebeli et al., 2013; Scipión et al., 2013; Grazioli et al., 2015), provided more detailed information and served as a control and reference for the calibration of the method to use the MRR data. It was used with a $75 \mathrm{~m}$ radial resolution, maximum radial distance $30 \mathrm{~km}$, and different types of scans within a repeating scanning sequence of $5 \mathrm{~min}$ (plan position indicator (PPI), range height indicator (RHI), vertical profiles). While the X-band radar could only be deployed during the summer campaign and had to be shipped back after completion in February 2016, the K-band radar sheltered by a radome could remain on site after the summer campaign. The radome significantly attenuates the signal (6.14 dB, Fig. 4 and Eq. 1 of Grazioli et al., 2017a), but it is necessary to protect the radar against the fierce winter winds in Adélie Land.

\subsubsection{Disdrometer and MASC}

The Biral VPF 730 disdrometer is also a non-capture instrument, which estimates the size and speed of airborne particles from the diffusion and diffraction of an infrared light beam within a $400 \mathrm{~cm}^{3}$ air volume. The volumetric sampling of the VPF730 presents an advantage over 2-D sampling instruments, which is that it does not miss particles with a much larger horizontal (due to strong wind) than vertical (falling) speed. The downside is that the instrument does not straightforwardly distinguish between falling and blowing snow (Bellot et al., 2011). A Biral proprietary algorithm directly provides precipitation rates from the size-speed matrix. Because this is based on various assumptions, including on the phase, shape and density of the particles, particularly unwarranted in the atypical Antarctic environment, the database described here presents the matrices rather than the estimated precipitation.

A MASC was deployed next to the disdrometer. This instrument collects high-resolution stereoscopic photographs of snowflakes in free fall while they cross the sampling area (Garrett et al., 2012), thus providing information about snowfall microphysics and particle fall velocity. The MASC uses three identical $2448 \times 2048$ pixels cameras (with a common focal point) with apertures and exposure times adjusted to trade off between the contrast on snowflake photographs and motion blur effects. The resolution is about $33 \mu \mathrm{m}$ per pixel. The cameras are triggered when a falling particle crosses two series of near-infrared sensors. A detailed description of the system and its calibration can be found in Garrett et al. (2012). Information from disdrometers (Souverijns et al., 2017) and more particularly from MASC images, after image processing, provides characterizations and classification of snow particles (Praz et al., 2017) that can be used to better process radar data.

\subsubsection{Precipitation gauge, meteorology, and setting of the instruments}

What fraction of snowfall a traditional precipitation gauge captures is unwarranted. On the other hand, unlike remote sensing instruments, the mass quantification of any captured snow is direct and straightforward. An OTT Pluvio2 precipitation gauge was deployed for the duration of the summer campaign. Snow falling in the instrument is definitely captured and weighted. The instrument used here was equipped with a manufacturer-design wind shield meant to limit wind impacts on capture efficiency. Further, the instru- 
Table 1. Summary of data from the APRES3 observation campaigns available by download from the PANGAEA repository (Berne et al., 2017) or by request to the authors. MASC data are provided for each picture taken, the taking of which varies with the occurrence of particle detection.

\begin{tabular}{|c|c|c|c|c|c|}
\hline \multirow[t]{2}{*}{ Instrument } & \multirow[t]{2}{*}{ Variables } & \multirow[t]{2}{*}{ Format/source } & \multirow[t]{2}{*}{ Time period } & \multicolumn{2}{|c|}{ Sampling } \\
\hline & & & & Time & Space \\
\hline Weather station & Temperature, moisture, wind & ASCII + NetCDF/PANGAEA & 21 Nov 2015-6 Feb 2016 & $30 \mathrm{~s}$ & local \\
\hline K-band MRR radar & Precipitation profiles (28 levels) & NetCDF/PANGAEA & 21 Nov 2015-11 Nov 2016 & $1 \mathrm{~h}$ & $\begin{array}{l}\text { Vertical: } \\
100 \mathrm{~m}\end{array}$ \\
\hline Pluvio2 weighing gauge & Surface precipitation & ASCII + NetCDF/PANGAEA & 17 Nov 2015-21 Jan 2016 & $1 \mathrm{~min}$ & local \\
\hline Biral VPF730 disdrometer & Size/speed matrices & ASCII + NetCDF/PANGAEA & 2 Dec 2015-23 Feb 2016 & $10 \mathrm{~min}$ & local \\
\hline MASC & $\begin{array}{l}\text { Snow particle classification and } \\
\text { microphysics }\end{array}$ & ASCII + NetCDF/PANGAEA & 11 Nov 2015-21 Jan 2016 & Variable & local \\
\hline X-band MXPol radar & $\begin{array}{l}\text { Polarimetric radar variables } \\
\text { and hydrometeor types }\end{array}$ & Request to authors & 21 Nov 2015 to 1 Feb 2016 & $5 \min$ & $\begin{array}{l}3-\mathrm{D}, \\
\text { radial: } 75 \mathrm{~m}\end{array}$ \\
\hline
\end{tabular}

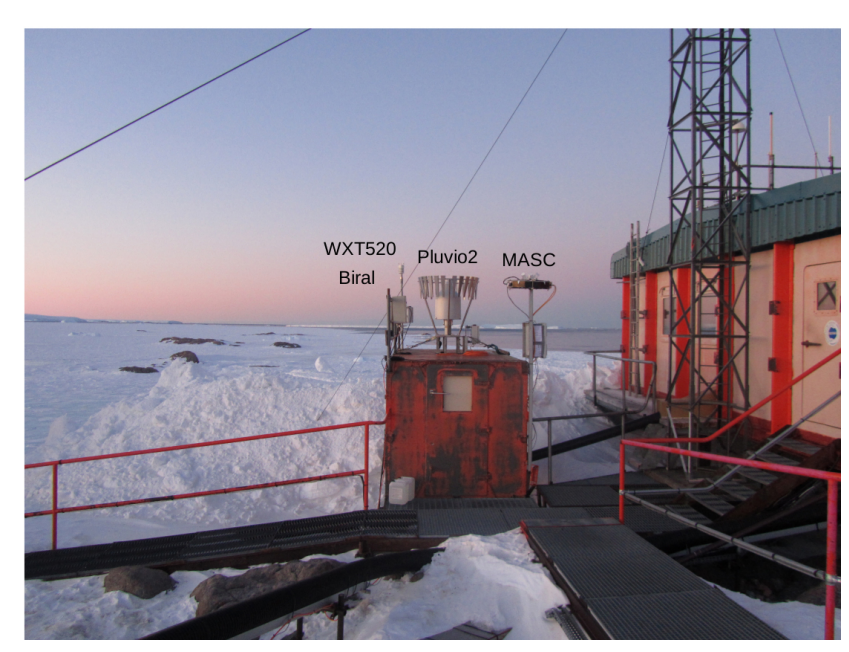

Figure 1. Setting of the in situ sensors (weather station WXT520, disdrometer Biral, snow gauge Pluvio 2 and MASC) on the roof of a small shelter close to other buildings.

ment was relatively shielded from the strongest wind due to its location, on the roof of a container but on the side of a building. The MASC and disdrometer were deployed at the same partially sheltered site (Fig. 1), the local meteorology of which was sampled locally by a Vaisala WXT520 weather transmitter, the principles, instrumental accuracy and performance of which can be found in the manufacturer's User's Guide (https://www.vaisala.com/sites/default/ files/documents/M210906EN-C.pdf, last access: 1 August 2018). Note that this station integrates an acoustic rain gauge not appropriate for measuring snowfall; thus, the deployment of the Pluvio2. The radars were closely located, within at most $200 \mathrm{~m}$ of the other instruments. A composite picture of the various instruments and instrument settings is provided by Fig. 2 of Grazioli et al. (2017a).

\section{Data, samples and conclusions}

Table 1 summarizes the data streams from the APRES3 measurement campaign. Grazioli et al. (2017a) extensively process and discuss the data from the different instruments. Further analyses and presentation are beyond the scope of this data paper, and only a few snapshots are provided to illustrate the content of the database. Figure 2 shows the cumulative precipitation during the intensive summer campaign, as yielded by the Pluvio2 snow gauge and the processed MRR at the lowest useful level and at $741 \mathrm{~m}$ above sea level. Only 28 out of 31 MRR levels are provided in the database. This is because several simplifications necessary for a tractable quantitative interpretation of radar signal power do not apply in the two lowest levels. Data processing is based on assumptions that are not valid as it may lead to overestimation of reflectivity (Peters et al., 2005). In the uppermost level, the data become noisy, as according to Kneifel et al. (2011), the detectability is highest close to the ground, at $-2 \mathrm{dBz}$ ( $35 \mathrm{GHz}$ equivalent) at $500 \mathrm{~m}$, but decreases with height to $3 \mathrm{dBz}$ at $3000 \mathrm{~m}$. Precipitation rates were retrieved from MRR data following Grazioli et al. (2017a): the reflectivity was converted into liquid water equivalent rate by fitting the prefactor and exponent of a Z-S relationship using carefully filtered nearby Pluvio2 data. Censoring the Pluvio2 data for windinduced biases such as vibrations and turbulence effects by cross-referencing with the MRR data removes up to $30 \%$ of the quantities (Grazioli et al., 2017a), as visible by the accumulation of the Pluvio2 in the time periods between snowfall events. As the Pluvio2 is a standard instrument but there is no standard correction method for wind effects, others might want to test other approaches, and the primary rather than the censored data are shown here and distributed in the database.

The MRR precipitation at the lowest useful level (341 ma.s.l.) is significantly less than that at $741 \mathrm{~m}$ a.s.l., showing that a significant fraction of the precipitation formed above sublimates in the dry katabatic air layer near the sur- 


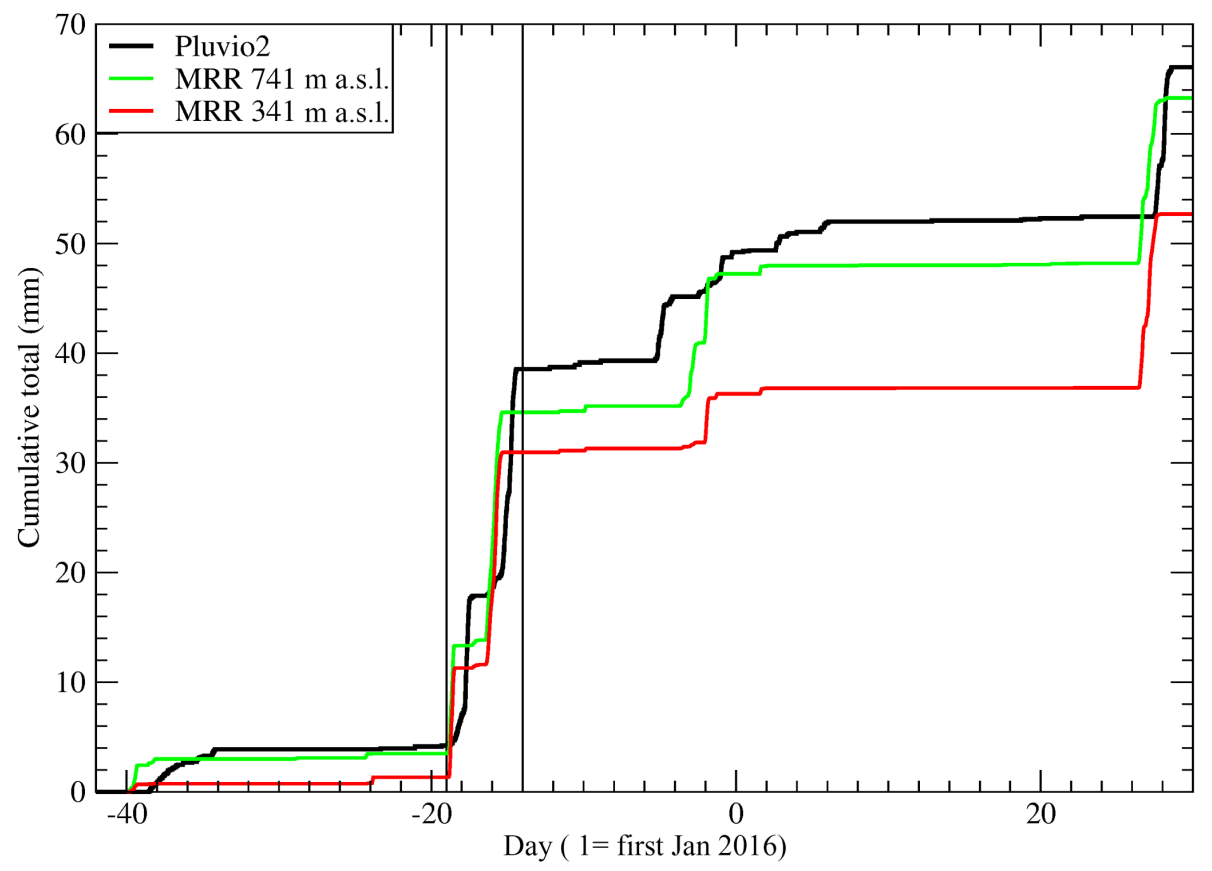

Figure 2. Cumulative precipitation during the APRES3 summer campaign, from the Pluvio2 and MRR instruments. Thin black vertical lines bracket the largest precipitation event in the period, from 12 to 17 December 2015. Precipitation from the MRR is reported for two levels above sea level, 341 and $741 \mathrm{~m}$.

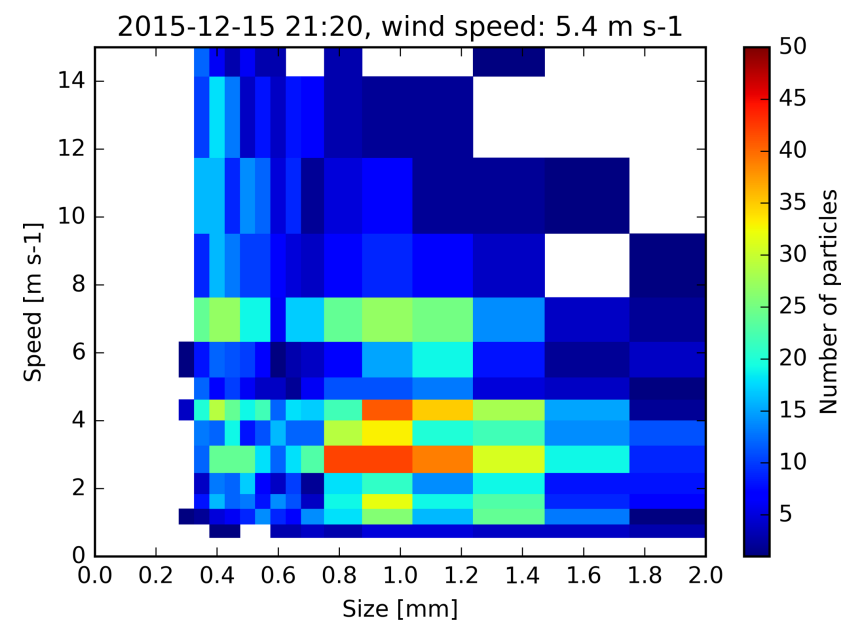

Figure 3. An example of the $21 \times 16$ fixed-level size-speed matrix of particle density distribution from the Biral disdrometer during the large precipitation event shown in Fig. 2. The date and time (15 December, 21:20 local time) and local wind speed $\left(5.4 \mathrm{~m} \mathrm{~s}^{-1}\right)$ are printed at the top of the graph.

face. Further observations show that this frequently occurs in all seasons of the year (see below). Meteorological and climate models suggest that at the full scale of the Antarctic ice sheet up to $17 \%$ of the precipitation evaporates in a dry surface layer before reaching the ground, and thus does not contribute to feeding the ice sheet (Grazioli et al., 2017b). Al- together, the 2015-2016 summer was relatively dry and few strong precipitation events occurred. One such event happened from 12 to 17 December 2015 (delineated by thin vertical black lines in Fig. 2), during which the largest part of the total cumulative precipitation this summer was recorded. Figure 3 shows an example of the Biral disdrometer sizespeed matrix during this event. The local wind was relatively strong $\left(5.4 \mathrm{~m} \mathrm{~s}^{-1}\right.$ averaged on the same $10 \mathrm{~min}$ as the matrix Fig. 3, with significant gusts in the period). Considering that the anemometer is set at a relatively sheltered place and thus underestimates the large-scale wind, a contribution of blowing snow to the disdrometer report is likely. However, a significant fraction of the density number of particles detected is associated with moderate speed below $4 \mathrm{~m} \mathrm{~s}^{-1}$. Large particles $(0.8-1.2 \mathrm{~mm})$ are detected, the fall speed of which may indeed be over $1 \mathrm{~m} \mathrm{~s}^{-1}$, as reported by the instrument.

Figure 4 shows the probability distribution function of the degree of riming of the snowfall particles as obtained by processing the MASC photographs. No less than 426229 photographs of falling snow particles were collected during the season. Each picture is processed as described in Praz et al. (2017). The database offers the processed results in the form of a classification, rather than the photographs themselves. Figure 4 cumulates all single estimates of the degree of riming in the database. The degree of riming is defined in this context as a continuous index between 0 (no riming on the particle detected) and 1 (fully rimed, graupel-like particle). Almost half of the particles are close to fully rimed, in- 


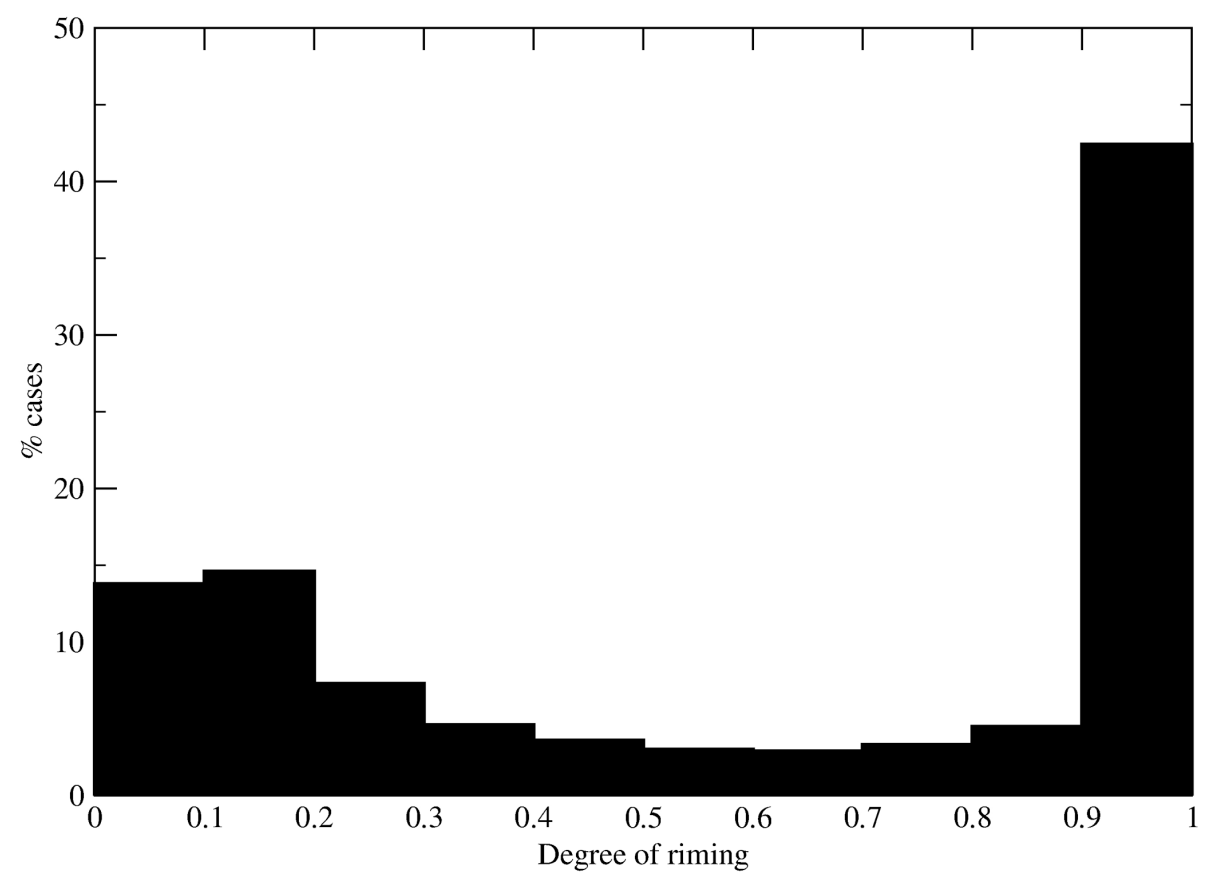

Figure 4. PDF of snow particle riming from the MASC data over the observation period.

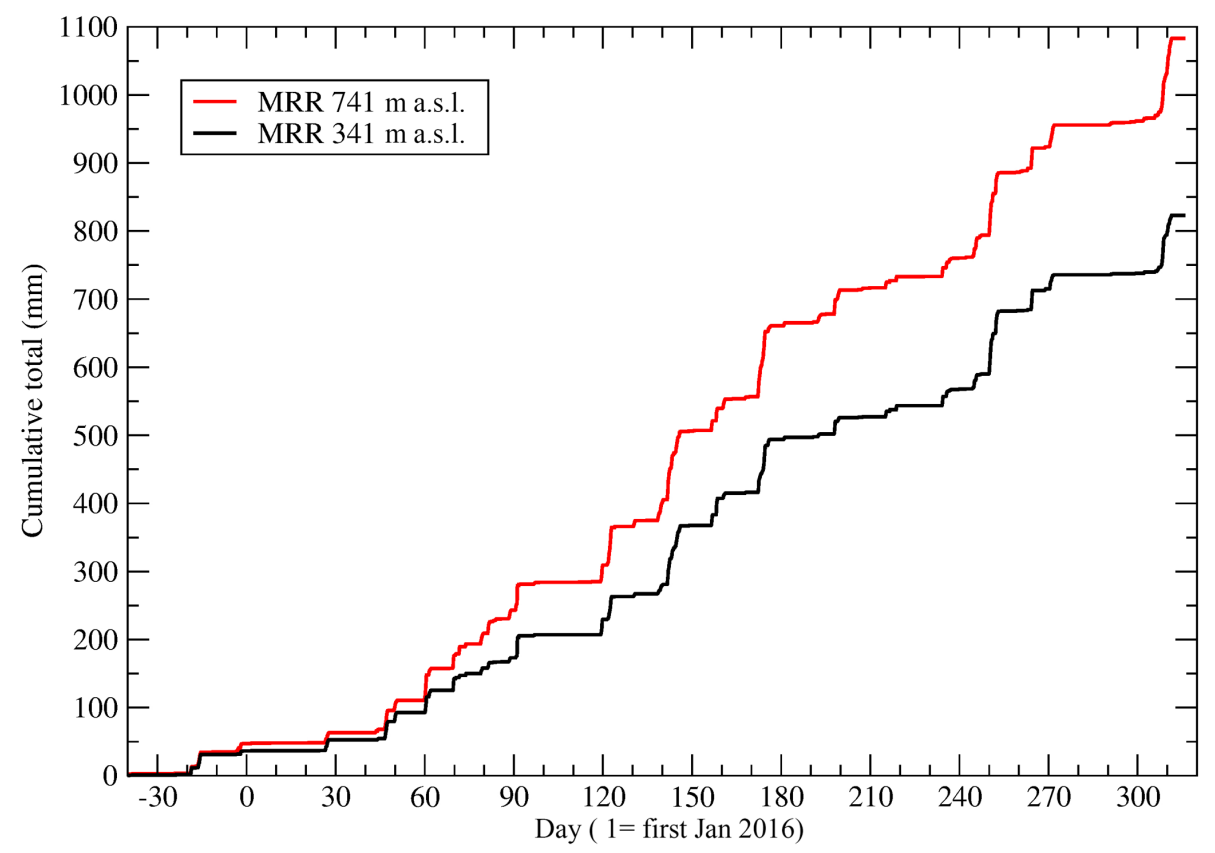

Figure 5. One year (November 2015-November 2016) of cumulative precipitation from MRR backscattering at 341 and $741 \mathrm{~m}$ above the surface.

dicating that cloud liquid water is very frequent in summer. Finally, Fig. 5 shows precipitation from the MRR dataset over the full record in the database, for more than a year from 21 November 2015 to 11 December 2016. Again, reports from two elevations, 341 and $741 \mathrm{~m}$ a.s.l., are displayed. This shows that at DDU, cumulated over a full year, $\sim 25 \%$ of the precipitation formed in the atmosphere sublimates before reaching the surface. 


\section{Data availability}

The APRES3 field campaign database is available in open access on PANGAEA, https://doi.org/10.1594/PANGAEA.883562 (Berne et al., 2017). MXPol data are too big to download from PANGAEA and are available on request to the authors.

\section{Conclusions}

In conclusion, observations at DDU carried out as part of the APRS3 project provide an unprecedented dataset of precipitation at the coast of Antarctica, complementing existing documentation efforts (Gorodetskaya et al., 2015) in a region which otherwise suffers from a severe shortage of such data. Our analysis of the data yields new insights into the characteristics and particularities of Antarctic snowfall, in particular that a large fraction of the precipitation formed in the atmosphere sublimates before reaching the surface. This information could only be obtained with instruments that can profile through the atmospheric layers, like radars here. However, the dataset goes beyond radar data and provides extensive complementary characterization of snow particle geometry and cumulative quantities of snowfall at the surface. Except for the dataset from the MXPol dual-polarization scanning radar during the summer campaign, the size of which (about $4 \mathrm{~TB}$ ) is too large to be shared online but can be obtained by direct request to the authors, all data are now distributed (Berne et al., 2017) and can be freely accessed from the PANGAEA repository (https://doi.org/10.1594/PANGAEA.883562). Table 1 provides a summary of the the variables and periods covered and distributed online for each instrument. At the time of writing this paper, the project carries on with continuous collection of precipitation profiles with the MRR, and a planned contribution to the Year Of Polar Prediction (YOPP, http://www.polarprediction.net/, last access: 1 August 2018) international austral special coordinated observation period from November 2018 to February 2019, the data from which will also be made available to the community. Because of a significant weather service's (Météo France) involvement including additional radiosoundings, in addition to the planned APRES3 contribution, DDU is identified as one of the YOPP observation hotspots for the southern special observing period.

Author contributions. $\mathrm{CG}, \mathrm{AB}$ and JG organized and ran the field campaigns. JG, $\mathrm{AB}, \mathrm{CDA}$ and $\mathrm{BB}$ developed radar data processing methods and produced data series. CG processed Biral disdrometer data and CP processed MASC data. All authors contributed data analysis, discussion and conclusions.
Competing interests. The authors declare that they have no conflict of interest.

Acknowledgements. We thank the French Polar Institute, which logistically supports the APRES3 measurement campaigns. We particularly acknowledge the support of the French National Research Agency (ANR) to the APRES3 project. The Expecting Earth-Care, Learning from the ATrain (EECLAT) project funded by the Centre National d'Etudes Spatiales (CNES) also contributed support to this work. The Swiss National Science foundation (SNF) is acknowledged for grant 200021_163287, financing the Swiss participation in the project. PANGAEA is gratefully acknowledged for hosting and distributing the APRES3 data. Steve Colwell, of the British Antarctic Survey, and two anonymous reviewers provided thoughtful comments and suggestions that helped correct and clarify a number of issues in the preliminary manuscript.

Edited by: David Carlson

Reviewed by: Steve Colwell and two anonymous referees

\section{References}

Arthern, R. J., Winebrenner, D. P., and Vaughan, D. G.: Antarctic snow accumulation mapped using polarization of $4.3-\mathrm{cm}$ wavelength microwave emission, J. Geophys. Res., 111, D06107, https://doi.org/10.1029/2004JD005667, 2006.

Behrangi, A., Christensen, M., Richardson, M., Lebsock, M., Stephens, G., Huffman, G. J., Bolvin, D., Adler, R. F., Gardner, A., Lambrigtsen, B., and Fetzer, E.: Status of high-latitude precipitation estimates from observations and reanalyses. J. Geophys. Res.-Atmos. 121, 4468-4486, 2016.

Bellot, H., Trouvilliez, A., Naaim-Bouvet, F., Genthon, C., and Gallée, H.: Present weather sensors tests for measuring drifting snow, Ann. Glaciol., 52, 176-184, 2011.

Berne, A., Grazioli, J., and Genthon, C.: Precipitation observations at the Dumont d'Urville Station, Adélie Land, East Antarctica, PANGAEA, 5 datasets, https://doi.org/10.1594/PANGAEA.883562, 2017.

Eisen O., Frezzotti, M., Genthon, C., Isaksson, E., Magand, O., van den Broeke, M. R., Dixon, D. A., Ekaykin, A., Holmlund, P., Kameda, T., Karlöf, L., Kaspari, S., Lipenkov, V. Y., Oerter, H., Takahashi, S., and Vaughan, G.: Snow accumulation in East Antarctica, Rev. Geophys. 46, RG2001, https://doi.org/10.1029/2006RG000218., 2007.

Fabry, F.: Radar meteorology: principles and practice, Cambridge University Press, 2015.

Funk, C., Verdin, A., Michaelsen, J., Peterson, P., Pedreros, D., and Husak, G.: A global satellite-assisted precipitation climatology, Earth Syst. Sci. Data, 7, 275-287, https://doi.org/10.5194/essd7-275-2015, 2015.

Garrett, T. J., Fallgatter, C., Shkurko, K., and Howlett, D.: Fall speed measurement and high-resolution multi-angle photography of hydrometeors in free fall, Atmos. Meas. Tech., 5, 26252633, https://doi.org/10.5194/amt-5-2625-2012, 2012.

Genthon, C., Six, D., Scarchilli, C., Giardini, V., and Frezzotti, M.: Meteorological and snow accumulation gradients across 
dome C, east Antarctic plateau, Int. J. Clim., 36, 455-466, https://doi.org/10.1002/joc.4362, 2015.

Goodison B. E., Louie, P. Y. T., and Yang, D.: Solid precipitation measurement intercomparison, WMO/TD - No. 872, WMO, Instrument and Observing Methods report No. 67, WMO, Geneva, 1998.

Gorodetskaya, I. V., Kneifel, S., Maahn, M., Van Tricht, K., Thiery, W., Schween, J. H., Mangold, A., Crewell, S., and Van Lipzig, N. P. M.: Cloud and precipitation properties from ground-based remote-sensing instruments in East Antarctica, The Cryosphere, 9, 285-304, https://doi.org/10.5194/tc-9-285-2015, 2015.

Grazioli, J., Lloyd, G., Panziera, L., Hoyle, C. R., Connolly, P. J., Henneberger, J., and Berne, A.: Polarimetric radar and in situ observations of riming and snowfall microphysics during CLACE 2014, Atmos. Chem. Phys., 15, 13787-13802, https://doi.org/10.5194/acp-15-13787-2015, 2015.

Grazioli, J., Genthon, C., Boudevillain, B., Duran-Alarcon, C., Del Guasta, M., Madeleine, J.-B., and Berne, A.: Measurements of precipitation in Dumont d'Urville, Adélie Land, East Antarctica, The Cryosphere, 11, 1797-1811, https://doi.org/10.5194/tc-111797-2017, 2017a.

Grazioli, J., Madeleine, J.-B., Gallée, H., Forbes, R. M., Genthon, C., Krinner, G., and Berne, A.: Katabatic winds diminish precipitation contribution to the Antarctic ice mass balance, P. Natl. Acad. Sci. USA, 114, 10858-10863, https://doi.org/10.1073/pnas.1707633114, 2017b.

Kneifel, S., Maahn, M., Peters, G., and Simmer, C.: Observation of snowfall with a low-power FM-CW K-band radar (Micro Rain Radar), Meteorol. Atmos. Phys., 113, 75-87, 2011.

Kneifel, S., Lerber, A., Tiira, J., Moisseev, D., Kollias, P., and Leinonen, J.: Observed relations between snowfall microphysics and triple-frequency radar measurements, J. Geophys. Res.Atmos., 120, 6034-6055, 2015.

König-Langlo, G., King, J. C., and Pettré, P.: Climatology of the three coastal Antarctic stations Dumont d'Urville, Neumayer, and Halley, J. Geophys. Res., 103, 10935-10946, https://doi.org/10.1029/97JD00527, 1998.

Krajewski, W. F. and Smith, J. A.: Radar hydrology: rainfall estimation, Adv. Water Resour., 25, 1387-1394, 2002.

Maahn, M. and Kollias, P.: Improved Micro Rain Radar snow measurements using Doppler spectra post-processing, Atmos. Meas. Tech., 5, 2661-2673, https://doi.org/10.5194/amt-5-2661-2012, 2012.

Mawson, D.: The home of the blizzard, William Heinemann, London, 1915.

Medina, S. and Houze Jr., R. A.: Small-scale precipitation elements in midlatitude cyclones crossing the California Sierra Nevada, Mon. Weather Rev., 143, 2842-2870, 2015.
Moisseev, D. N., Lautaportti, S., Tyynela, J., and Lim, S.: Dualpolarization radar signatures in snowstorms: Role of snowflake aggregation, J. Geophys. Res.-Atmos., 120, 12644-12655, 2015.

Nilu, R.: Cold as SPICE, Meteorol. Tech. Int., April 2013, 148-150, 2013.

Palerme, C., Kay, J. E., Genthon, C., L’Ecuyer, T., Wood, N. B., and Claud, C.: How much snow falls on the Antarctic ice sheet?, The Cryosphere, 8, 1577-1587, https://doi.org/10.5194/tc-8-15772014, 2014.

Palerme, C., Genthon, C., Claud, C., Kay, J. E., Wood, N. B., and L'Ecuyer, T.: Evaluation of Antarctic precipitation in CMIP5 models, current climate and projections, Clim. Dynam., 48, 225239, https://doi.org/10.1007/s00382-016-3071-1, 2016.

Palerme, C., Claud, C., Dufour, A., Genthon, C., Kay, J. E., Wood, N. B., and L'Ecuyer, T.: Evaluation of Antarctic snowfall in global meteorological reanalyses, Atmos. Res., 48, 225-239, https://doi.org/10.1007/s00382-016-3071-1, 2017.

Parish, T. R. and Bromwich, D. H.: The surface wind field over the Antarctic ice sheets, Nature, 328, 51-54, 1987.

Peters, G., Fischer, B., Münster, H., Clemens, M., and Wagner, A.: Profiles of raindrop size distributions as retrieved by Microrain Radars, J. Appl. Meteorol., 44, 1930-1949, https://doi.org/10.1175/JAM2316.1, 2005.

Praz, C., Roulet, Y.-A., and Berne, A.: Solid hydrometeor classification and riming degree estimation from pictures collected with a Multi-Angle Snowflake Camera, Atmos. Meas. Tech., 10, 13351357, https://doi.org/10.5194/amt-10-1335-2017, 2017.

Schneebeli, M., Dawes, N., Lehning, M., and Berne, A.: Highresolution vertical profiles of X-band polarimetric radar observables during snowfall in the Swiss Alps, J. Appl. Meteorol. Climatol., 52, 378-394, 2013.

Schneider, U., Becker, U. A., Finger, P., Meyer-Christoffer, A., Ziese, M., and Rudolf, B.: GPCC's new land surface precipitation climatology based on quality-con,trolled in situ data and its role in quantifying the global water cycle, Theor. Appl. Climatol., 115, 15-40, https://doi.org/10.1007/s00704-013-0860-x, 2014.

Scipión, D. E., Mott, R., Lehning, M., Schneebeli, M., and Berne, A.: Seasonal small-scale spatial variability in alpine snowfall and snow accumulation, Water Resour. Res., 49, 1446-1457, 2013.

Souverijns, N., Gossart, A., Lhermitte, S., Gorodetskaya, I. V., Kneifel, S., Maahn, M., and van Lipzig, N. F. L.: Estimating radar reflectivity - snow fall rate relationships and their uncertainties over Antarctica by combining disdrometer and radar observations, Atmos. Res., 196, 211-223, https://doi.org/10.1016/J.atmosres.2017.06.001, 2017.

Witze, A.: Climate science Antarctic cloud study takes off, Nature, News in Focus, 529, 12 pp., 2016. 